necessary assumption (not without considerable justice) rather than an idea to be confirmed or refuted. Perhaps more significantly, the aims of palaeomagnetism were expanded to cover not just the relatively narrow geophysical problem of tracing the geomagnetic field through time but also the much wider geological problem of delineating the movements of land masses. Or to put it another way, the wider geological community had begun to discover the Earth's magnetic field. But in bringing the larger and smaller communities together it was inevitable that henceforward the geological aspects of the subject should dominate the geophysical ones.

Nevertheless, fundamental work on the origin and long-term behaviour of the geomagnetic field continued throughout the earth science revolution, albeit on a relatively small scale; and some of it (most notably the construction of the geomagnetic polaritytime scale) even found important geological application in its own right. In recent times, however, there has been a noticeable upsurge of interest in the study of the palaeomagnetic field for its own sake, almost 20 reports having been published in the last six months alone. And it is apparent from the diversity of subjects covered that the detailed delineation of the history of the Earth's magnetic field is still far from complete; even the comfortably familiar is not beyond question.

The article by Verosub on page 707 of this issue of Nature offers a good case in point. Since the pioneering work of Elsasser (Phys. Rev., 69, 106; 1946 and 70, 202; 1946) in the mid1940 s, the self-reversing dynamo has come to be accepted as the only viable source of the main dipole field. There are problems in establishing the validity of the dynamo model because, although mechanical analogues can reproduce field reversals and field intensity fluctuations, they are a poor substitute for the complex motions thought to occur in the Earth's core; and the motions themselves have not so far proved amenable to satisfactory mathematical treatment. Nevertheless, the self-reversing dynamo has reigned supreme if only because every other idea has been ruled out as impossible. Or so we thought. Verosub, however, offers a delightfully simple (in principle) alternative involving two opposing fields whose magnitudes vary with time. This model poses its own problems, of course-most notably the need to find the origin of the second field (the first presumably being produced by a nonself-reversing dynamo in the fluid outer core). But by the same token, it also brings the whole question of field origin back within the scope of non-magnetohydrodynamic man.
In support of his two-component field source hypothesis Verosub quotes Wilson's (Geophys. J., 28, 295; 1972) discovery that there are significant differences between the time-averaged mean pole positions of normal and reversed populations-differences which Verosub believes might indicate the dominance of a distinct field source in each polarity state. Using Upper Tertiary and Quarternary palaeomagnetic data from the Soviet Union, Wilson showed that whereas both normal and reversed poles tend to lie on the far side of the present geographical pole from the observing site, the 'far-sidedness' in the reversed case is significantly greater than in the normal. Earlier, Wilson (Geophys. J., 19, 417; 1970) has interpreted far-sided poles in terms of an axial dipole displaced a small distance northwards from the centre of the Earth; and this is a theme to which

\title{
Time to ecological equilibrium
}

\section{Responses from Leigh Van Valen, T. R. E. Southwood and Donald Strong}

Strong (Proc. natn. Acad. Sci. U.S.A., 71, 2766; 1974) has pointed out flaws in the correlation shown by Southwood (J. Anim. Ecol., 30, 1 ; 1961) between subfossil records of trees and the associated insect species richness. He showed that Southwood's correlation was confusing by demonstrating a correlation between the present range of British trees and the number of associated insect species. He also estimated that the time required for tree genera introduced into Britain to become saturated with herbivores was only a few decades or hundreds of years-the evidence for this being that the regression of herbivores on the distribution of non-native trees does not differ significantly from that of native genera. Peter D. Moore discussed his findings in Nature (252, 14; 1974).

- Leigh Van Valen now writes that Strong's last conclusion is unjustified because " analysis of data from Strong's Fig. 3 shows that the slope of regression for introduced genera not only does not differ significantly from that for native genera, it also does not differ significantly from either 0 or 1 , whether or not two ambiguous genera (apple and lime) are included. Therefore the conclusion, while quite possibly true, is not supported by the data."

- Peter Moore, who expressed in his article in Nature reservations about Strong's evidence against an increase in species richness over geological time, now adds, "I agree that one cannot justify a rapid attainment of saturation by insect species on the basis of Strong's data. On the contrary, one might predict that if any non-native tree species in Britain were to extend its range significantly then a rise in associated insect species might be expected. The question of changes in richness during geological time remains unsettled.

- T. R. E. Southwood emphasises that although he is responsible for the correlation between geological time and species richness, in his original paper he also pointed out the relationship between the present range of trees and their associated species richness (see Proc. Hawaiian ent. Soc., 17, 299; 1960; XI Int. Kongress fur Ent. 1, 651-655; 1961 and Nature, 253, 313; 1975).

- Donald Strong replies: "Van Valen is wrong. Given the correlation coefficient values characteristic of host plant-insect species richness relationships, one does not expect high significance values for comparisons of few points; my conclusions are not contingent upon the significance of the correlation of introduced points. Since the original publication, however, I have been supplied range data on two additional introduced hosts, walnut and spruce (through the great courtesy of Dr Perring's unit at Monk's Wood). With these included, the correlation coefficient of introduced taxa is significantly greater than 0 $(r=0.635 ; 0.05<P<0.1)$. These data will be included in a forthcoming paper dealing with other pest species over these same hosts. This new paper will demonstrate rapid species saturation as does the first. As well, I have found rapid saturation in a totally different plant-insect system (Science, 185, 1064-1066; 1974).

"Southwood's comment is correct, and Moore is confused, as reference to my original paper will verify. One of my main theses was that pest species richness will vary as host range varies, quickly, be the species introduced or native. My alternative to the non-asymptotic model was clearly stated to be an asymptotic one.

"Please note also that there is an error in my original paper; in Fig. 3 'common maple' sits not to the left of the regression line as I have plotted it, but virtually on top of it. This correction reinforces my conclusions." 